\title{
Hovmöller diagrams of climate anomalies in NCEP/NCAR reanalysis from 1948 to 2009
}

\author{
Klemens Hocke • Niklaus Kämpfer
}

Received: 21 May 2009/ Accepted: 6 November 2009/Published online: 20 November 2009

(C) Springer-Verlag 2009

\begin{abstract}
Atmospheric and oceanic reanalysis data of the past 60 years are visualized by time-latitude cross sections which inform about temporal and latitudinal variability, changes, and meridional circulation of the climate system on time scales from years to decades. The diagrams ease the understanding of climate dynamics in a similar way as the Hovmöller diagram has clarified the zonal propagation of synoptic-scale waves in a latitude band. Thus the timelatitude cross sections are referred to as Hovmöller diagrams of climate anomalies. Various parameters are selected at the Earth's surface level: air temperature, pressure, sea surface temperature, column-integrated atmospheric water vapour (IWV), surface relative humidity, and surface wind. Contour lines of one parameter are overlayed on the color image of the other parameter so that relations and coincidences of trends, oscillations, and sudden changes of the climate are revealed. Temporal variations of IWV and surface relative humidity appear to be related to the strength of the Southern polar front jet. In case of ENSO 1997/1998, the equatorial IWV enhancement is accompanied by acceleration of the meridional circulation cells of the Southern Hemisphere. Meridional surface wind data suggest the existence of double polar cells in both hemispheres. The Southern polar cells switched to a higher circulation speed in 1997, and surface relative humidity increased over Antarctica. A sudden and persistent decrease of surface pressure occurred in Antarctica around 1980. Since 2000, a rapid increase of surface air temperature, sea surface temperature, and IWV occurs
\end{abstract}

K. Hocke $(\bowtie) \cdot$ N. Kämpfer

Institute of Applied Physics and Oeschger Centre for Climate

Change Research, University of Bern, Sidlerstr. 5,

3012 Bern, Switzerland

e-mail: klemens.hocke@iap.unibe.ch in the Northern Hemisphere. These results of NCEP/NCAR reanalysis have to be cross-validated with other reanalyses, climate models, and pure observations which will be a major endeavour.

Keywords Climate - Diagnostics · Abrupt - Change · Variability

\section{Introduction}

Anthropogenic emissions of greenhouse gases such as carbon dioxide and methane induce a warming of the troposphere and the oceans. The warming process changes the hydrological cycle and the circulation of the ocean-atmosphere system (Held and Soden 2006). The evaporation rate of water is greater for a warmer sea surface, warmer air, and stronger surface winds. Since atmospheric water vapour absorbs the thermal radiation of the Earth, an amplification of human-induced global warming by natural processes is possible (Gillett et al. 2005; Shindell et al. 1999; Trenberth et al. 2005; Willett et al. 2007).

This example of a long interaction chain with influences on various atmospheric parameters motivates us to perform a combined analysis of trends and oscillations of surface air temperature, sea surface temperature, surface pressure, column-integrated water vapour (IWV), surface relative humidity, and surface wind based on meteorological and oceanic reanalysis data from January 1948 to July 2009. Climate change is analyzed by means of time-latitude cross sections which we like to call Hovmöller diagrams of climate anomalies.

The dynamic visualization of the anomalies reveals relationships and interdependencies of atmospheric and oceanic parameters. In the introduction, we omit a 
description of previous studies on atmospheric variability, circulation cells, abrupt climate change, and trends. Instead we refer later to some of these works for interpretation of certain features appearing in the Hovmöller diagrams.

Section 2 explains and discusses the NCEP/NCAR reanalysis data. Sections 3 and 4 describe advantages, limitations, and potential of Hovmöller diagrams for climate change research and intercomparisons. Details of the data analysis are given in Sect. 5. Section 6 contains the Hovmöller diagrams of seven climate parameters over the last 60 years. The results are discussed in view of abrupt climate change, teleconnection, and meridional propagation of climate anomalies.

\section{Reanalysis data}

The atmospheric parameters temperature, pressure, column-integrated water vapour (IWV or precipitable water), surface relative humidity, and surface wind are provided by the NCEP/NCAR Reanalysis 1 project since 1948 (Kalnay et al. 1996; Kistler et al. 2001). Monthly averages on global grids $\left(2.5^{\circ}\right.$ resolution in latitude and longitude) are available at the Climate Diagnostics Center of NOAA's Earth System Research Laboratory (http://www.cdc. noaa.gov/). A reanalysis is an integration of historical observations and model simulations using data assimilation techniques (Chen and Bosilovich 2007). The NCEP/NCAR Reanalysis 1 data assimilation system consist of the NCEP global spectral model and a 3-D variational (3DVAR) scheme cast in spectral space denoted spectral statistical interpolation. During the last decade, the quality of reanalysis data significantly improved (though there seems to be a lack of error assessment since error bars are not provided by the reanalysis data centers).

Data of the sea surface temperature are based on the International Comprehensive Ocean-Atmosphere Data Set (ICOADS, http://icoads.noaa.gov/) and are available at the Climate Diagnostics Center (NOAA Extended Reconstructed Sea Surface Temperature Version 3b).

The results derived from reanalysis data should be treated with some caution since the results can be biased by different observing systems at different times. According to Kistler et al. (2001), the reanalysis variables can be classified by several types. Type A variables (e.g., temperature, pressure, rotational wind) are strongly influenced by the available observations and are the most reliable product of the reanalysis. Discontinuities resulting from the introduction of satellite measurements into the reanalysis (in the 1970s) are much smaller at the surface than at upper altitudes. Therefore we concentrate in the present study on surface level data. In addition, the problem of the slow adjustment time of old radiosondes to the thin air at upper altitudes should be not relevant for the present study. Type $B$ variables (e.g., moisture variables) are influenced by both the observations and the model and are less reliable. Water vapour measurements are relatively rare before 1970 and not so accurate as temperature or pressure measurements. The old hygrometers had calibration errors, a slow response time, and depended on manual operation. Only during the last $2-3$ decades, modern hygrometers such as electronically-steered dew point mirror hygrometers have been implemented in the network of meteorological stations and radiosondes. A time-latitude cross section of IWV can help to reveal an observing system-induced discontinuity of the reanalysis data.

Many scientists have contributed to the NCEP/NCAR Reanalysis 1 project, and many shortcomings of the reanalysis data set during the beginning years of the project have been recognized and removed. Simmons et al. (2004) compare surface air temperatures from CRU (monthly station data without model), ERA-40 (reanalysis project of ECMWF), and NCEP/NCAR reanalysis. The warming trend of the Northern Hemisphere from 1979 to 2001 is $+0.30 \mathrm{~K} / \mathrm{dec}$ ade for CRU, $+0.27 \mathrm{~K} / \mathrm{dec}$ de for ERA-40, and $+0.19 \mathrm{~K} /$ decade for NCEP/NCAR reanalysis. The possible underestimation of the trend of surface air temperature by NCEP/NCAR reanalysis might be due to a lack of assimilation of surface station data. On the other hand, it is questionable if CRU represents the "truth" since there are not enough stations in oceanic areas. Global or hemispheric mean temperatures derived from pure observations can be biased by gaps of the observing system. Interannual oscillations of the surface air temperature appear quite similar in the time series of all three data sets. A possible discontinuity in the 1970s (caused by the inclusion of satellite data) is not present in the comparison plot of NCEP/NCAR reanalysis and the pure station data of CRU (Fig. 1 of Simmons et al. (2004)).

\section{Method of visualization}

Climate change happens in the 4-D space-time continuum of the Earth, and 2-D cross sections are common for visualization of model results and observations, e.g., world maps of linear trends of temperature. The disadvantage of world maps of linear trends is the loss of information on temporal oscillations and sudden changes of circulation cells. A dynamic view on climate change is provided by time-latitude cross sections (on the expense of the longitudinal dependence). In some cases, 3-D transport processes and atmospheric fields may lead to misinterpretations in the time-latitude cross sections. Thus the Hovmöller diagrams should be used in addition to other visualizations. Peterson and Baringer (2009) included 


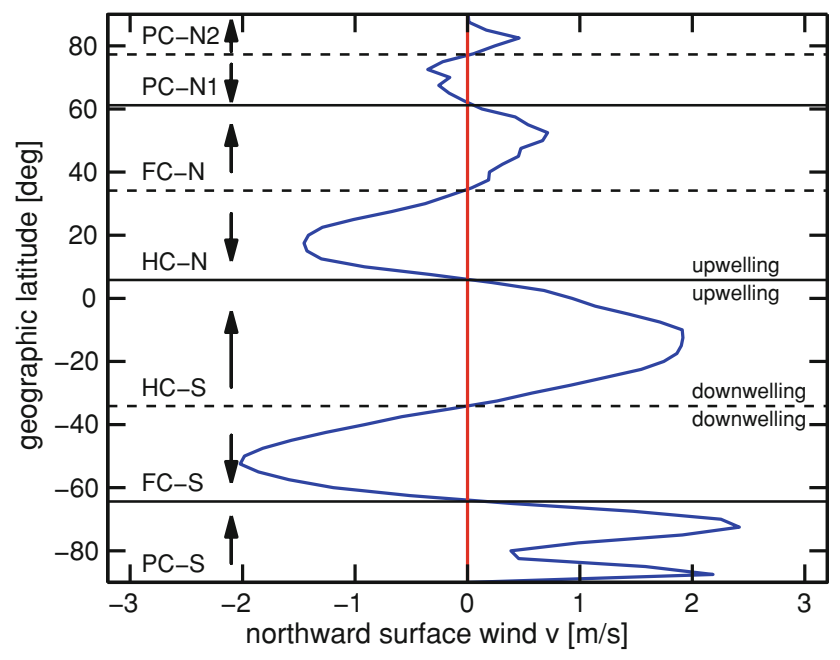

Fig. 1 Mean state of the meridional surface wind of NCEP/NCAR reanalysis averaged from 1970 to 1990 . The arrows denote the direction of the meridional surface wind within the polar, Ferrel, and Hadley circulation cells. Upwelling and downwelling regions associated with converging and diverging winds are shown by the solid and dashed horizontal lines, respectively

Hovmöller diagrams in their assessment of the state of the Earth's climate, and several meteorological agencies offer overview diagrams of reanalysis data (e.g., JRA25 Atlas of Japan Meteorological Agency at http://ds.data.jma.go.jp/ $\mathrm{gmd} / \mathrm{jra} / \mathrm{atlas} / \mathrm{eng} / \mathrm{atlas}$-tope.htm). Such climate services are essential to expand the circle of scientists who investigate and discuss climate data.

The idea of the time-latitude cross section is inspired by Maunder's butterfly diagram of sunspots which is invaluable for understanding of the solar cycle (Maunder 1904). The butterfly diagram illustrates the 11-year "travel" of magnetic sunspots from middle to low heliographic latitudes and the reversal of the magnetic polarity of the northern and southern sunspots with a period of about 22 years. In meteorology, the Hovmöller diagram is frequently used for the study of the zonal propagation of synoptic-scale waves in a selected latitude band or along a storm track (Hovmöller 1949; Martius et al. 2006). Max et al. (1993) show an example of a 3-D Hovmöller diagram where latitude, longitude, and time are used as axes in an illustration about the evolution, propagation, and dissipation of rain areas in Eastern Asia (20 mm per day-isosurface of precipitation).

In the present study we stay on a lower illustration level and investigate the benefits of time-latitude cross sections of surface parameters (Hovmöller diagrams) for climate change studies. The Hovmöller diagrams can inform about the meridional propagation of climate anomalies as well as about acceleration and meridional shift of circulation cells. A long-term average of the meridional surface wind of NCEP/NCAR reanalysis from 1970 to 1990 shows the characteristics of the Hadley, Ferrel, and polar circulation cells of both hemispheres in Fig. 1. Due to the different topography the circulation speed is much stronger in the Southern than in the Northern hemisphere. The appearance of double polar cells in both hemispheres is somewhat surprising and later we see that the circulation speed of the Southern polar cells is strongly time-dependent.

The acceleration or deceleration of an atmospheric circulation cell or the meridional shift of a cell can be analyzed by means of the Hovmöller diagram of the meridional surface wind. Further the increase or decrease of up- and downwelling air in the convergence and divergence zones of the meridional surface wind might be traceable as a temporal pressure anomaly in the Hovmöller diagram of surface pressure.

\subsection{Role of visualization for error assessment} and climate change research

The visualization of data from observations, reanalyses, and climate models is essential for discovery and understanding of climate change processes. Visualization methods such as the Hovmöller diagram are also invaluable for intercomparison, error assessment, and improvement of observing systems, reanalyses, and climate models.

We suggest a flow chart for optimization of reanalyses, models, and pure observations which is depicted in Fig. 2. The flow chart emphasizes the roles of data analysis, error assessment, and harmonization for climate change research. The present study is mainly about the data visualization of NCEP/NCAR reanalysis. Some interpretations and climate change results are suggested but these results have to be confirmed by other reanalyses, models, and pure observations before the results can be seriously considered. However we can already say that Hovmöller diagrams of climate parameters are well suited for detection of sudden climate changes, cross-validation of data sets, and localization of bugs in observations and models. Hansen et al. (2007) intercompared anomalies of surface air temperature in climate simulations and observations by means of timelatitude cross sections. The diagrams gave insight whether the models can capture ENSO variability and cooling by volcanic eruptions.

A similar optimization strategy as in Fig. 2 was suggested by Raschke et al. (2006) in an assessment of radiation budget data of ISCCP (International Satellite Cloud Climatology Project) and GEWEX-SRB (Global Energy and Water Cycle Experiment - Surface Radiation Budget Project). They found seasonal and interannual variations in the time series of the difference of the infrared radiation flux of ISCCP and GEWEX-SRB. These variations were due to serious errors in ancillary data which had to be corrected before reprocessing of the radiation budget data. 


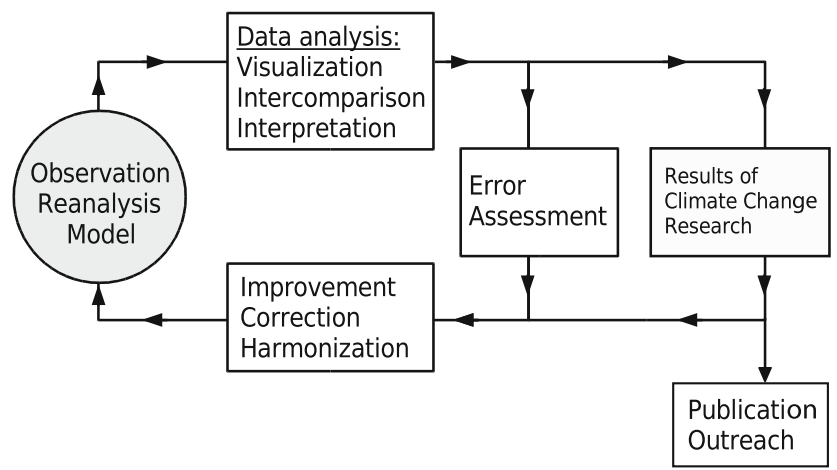

Fig. 2 Flow chart for optimization of observations, reanalyses, and models

Study of the temporal behaviour of the difference of both data sets is straightforward for finding error sources and harmonizing of data sets.

\section{Data analysis}

For a better recognition of the temporal and latitudinal changes of the climate parameters, we subtract the zonal mean state and deseasonalize the reanalysis data. The mean state $X_{\mathrm{m}}(\vartheta)$ of the zonal average of a parameter $X$ at the latitude $\vartheta$ is derived by averaging of $X(t, \vartheta)$ over the time interval from 1970 to 1990 (keeping the latitude $\vartheta$ fixed). The choice of the time interval from 1970 to 1990 for calculation of the mean state is consistent for all climate parameters. The selected time interval is roughly the middle third of the whole series from 1948 to 2009. The minor quality of some climate parameters such as surface relative humidity or column-integrated water vapour at times before 1970 led to this choice since the mean states would be falsified by the first third of the reanalysis data. As consequence the colour bars of the anomaly diagrams would be not centered at zero for some climate parameters.

The anomaly $\Delta X(t, \vartheta)$ describes the deviations from the mean state and is defined by

$\Delta X(t, \vartheta)=X(t, \vartheta)-X_{\mathrm{m}}(\vartheta)$

where the time series $X(t, \vartheta)$ were deseasonalized by means of a digital nonrecursive, finite impulse response (FIR) low-pass filter performing zero-phase filtering by processing the time series in forward and reverse direction. The filter order corresponds to a time window of three times of the cutoff period of 1.5 years. Thus the filter quickly reacts to temporal changes of the time series, and oscillations with periods $<1.5$ years are suppressed. Further an Hamming window has been selected for the filter (Shenoi 2006).

For a fast adjustment of the filter at the start and at the end of the time series, the series were extended by
10 year-intervals containing just the mean value of the first and the last five observation years respectively. Extension of the series by constant mean values has been favoured since its influence on trend interpretation is easier to judge than in case of extension of the series by extrapolation of linear trends. Padding of constant mean values possibly leads to a slight underestimation of the anomalies $\Delta X(t, \vartheta)$ at the edges.

At some places of the next section, linear trends are given. Averages (global mean, hemispheric mean, means of polar regions or latitudinal belts) were made with area weighting by the cosine of the latitude of each grid point. In case of the sea surface temperature, the latitudinal change of the sea-land distribution was considered by multiplication of the zonal means with additional weighting factors (number of sea grid points divided by number of all grid points at a given latitude).

The trends and their errors are calculated by multiple linear regression of the monthly, deseasonalized time series from 1975 to 2008. The errors come from the residuals of the straight line fit and are mainly due to fit uncertainties arising from interannual and decadal oscillations. The selected time interval (January 1975-December 2007) amounts to 33 years which is an integer multiple of the solar cycle period of 11 years. This choice minimizes the contamination of the linear trend by solar cycle warming. Tung and Camp (2008) derived an amplitude of about $0.1 \mathrm{~K}$ for the signal of the solar cycle in surface air temperature of NCEP/NCAR and ERA-40 reanalyses. If we assume that a trend is calculated over a time interval of 1.5 solar cycles and that the time interval begins at solar minimum, the solar cycle effect would contribute $0.02 \mathrm{~K} /$ decade to the trend.

The time interval from 1975 to 2008 has been selected since greenhouse warming strongly increased during this time. Indeed, linear trend analysis is actually not adequate for the nonlinear evolution of some climate parameters. To some extent, the reader can estimate nonlinear trends by means of the Hovmöller diagrams of the climate anomalies which are shown later. In case of surface air temperature we additionally present a linear trend analysis with a moving 11 year-data window illustrating the problem of distinction between temporal oscillations and linear trends

\section{Results}

\subsection{Temperature trend}

The anomaly of surface air temperature has been calculated by means of Eq. 1) and is shown in Fig. 3. Temperature anomalies are strongest in the polar regions during the last three decades. The linear trend of polar surface air 
temperature is calculated by multiple linear regression and is $+0.77 \pm 0.15 \mathrm{~K} /$ decade (obtained for geographic latitudes $|\vartheta| \geq 70^{\circ}$ and for the time interval 1975-2008). Comiso (2003) found surface air temperature trends ranging from +0.7 to $+1.5 \mathrm{~K} /$ decade in satellite thermal infrared data of the Arctic from 1981 to 2001. Steig et al. (2009) reported a warming of $+0.12 \pm 0.1 \mathrm{~K} /$ decade for the mean surface air temperature of Antarctica from 1957 to 2006 (values from Table 1 of corrigendum).

Temperature trends of the polar regions are still controversly discussed since the spatio-temporal variability of the polar atmosphere, ice coverage, and oceanic currents is high, while long-term in situ measurements are rare. The report of the Intergovernmental Panel on Climate Change (IPCC) gives no numbers of observed temperature trends in the polar regions and states that arctic temperatures increased almost twice the global average rate in the past 100 years and that there was a warm period between 1925 and 1945 (IPCC 2007).

Around 1980 in Fig. 3, the blue color changes to red color in the Antarctic indicating a sudden change of the climate. This feature may suggest a relationship between climate change and the ozone hole which rapidly grew up in the 1980s. Coincidently a warming signal occurs in the Arctic around 1980. In the Northern Hemisphere the warming process increases since 1980 and expands from high to low latitudes. The impact of stratospheric variability on tropospheric climate change is a challenge for general circulation models. Dall'Amico et al. (2009) found a significant increase of surface air temperature in the Arctic when the Hadley Centre HadGEM1 coupled ocean atmosphere model ran with improved ozone data and with

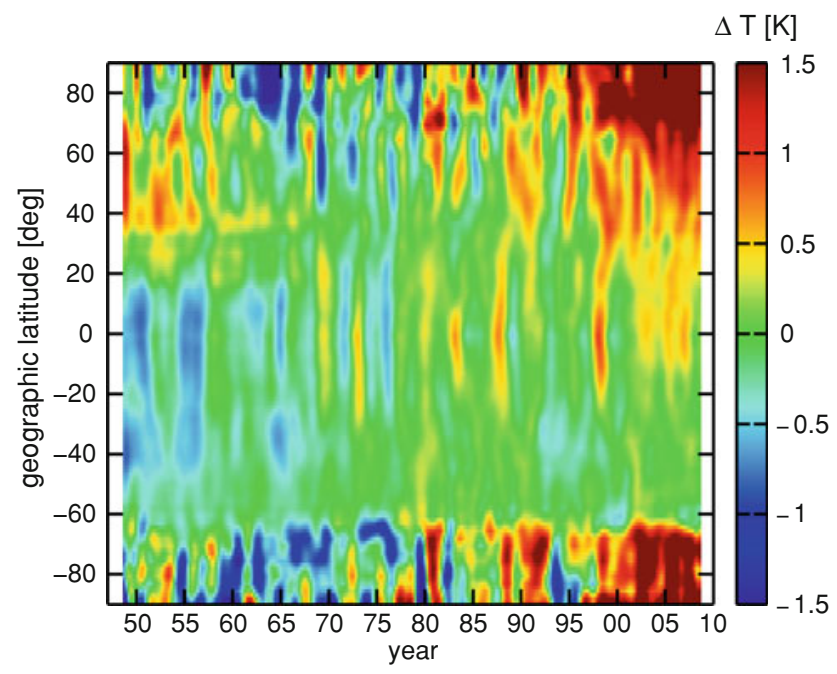

Fig. 3 Anomaly of surface air temperature derived from global NCEP/NCAR reanalysis data (Eq. 1). The anomaly describes deviations from the mean state (e.g., due to global warming and natural oscillations) imposed quasi-biennial oscillation (QBO) of stratospheric equatorial zonal wind. Hartmann et al. (2000) argued that strong synergistic interactions between stratospheric ozone depletion and greenhouse warming are possible via the annular modes producing rapid climate change as response to modest external forcing.

In the tropics, interannual variations of the temperature are present, e.g., a strong increase due to the El Niño Southern Oscillation (ENSO) in 1997/1998. The linear trend of temperature is around $+0.11 \pm 0.02 \mathrm{~K} /$ decade in the tropics (from $10^{\circ} \mathrm{S}$ to $10^{\circ} \mathrm{N}, 1975-2008$ ) and vanishes at latitudes from $10^{\circ} \mathrm{S}$ to $60^{\circ} \mathrm{S}:-0.01 \pm 0.09 \mathrm{~K} /$ decade. The linear trend of the global mean temperature is $+0.18 \pm 0.06 \mathrm{~K} /$ decade $(1975-2008$, NCEP/NCAR). The IPCC gives a value of $+0.13 \pm 0.03 \mathrm{~K} /$ decade as the linear warming trend of the global surface air temperature over the last 50 years (IPCC 2007). We also computed $+0.13 \pm 0.03 \mathrm{~K} /$ decade as trend of the global mean temperature for NCEP/NCAR reanalysis from January 1957 to January 2007. Table 3.3 of the IPCC Climate Change 2007 report shows values between +0.163 and $+0.170 \mathrm{~K} /$ decade as global warming trend of surface air temperature (land and sea) from 1979 to 2005 (analyses of CRU/UKMO, NCDC, and GISS). Thus the global warming trend derived from the data set of Fig. 3 is consistent with the values of the IPCC report.

A way for illustration of the temporal and latitudinal dependence of the linear trend of surface air temperature is shown in Fig. 4. The linear trends have been calculated by means of an 11 year-window which has been moved with a

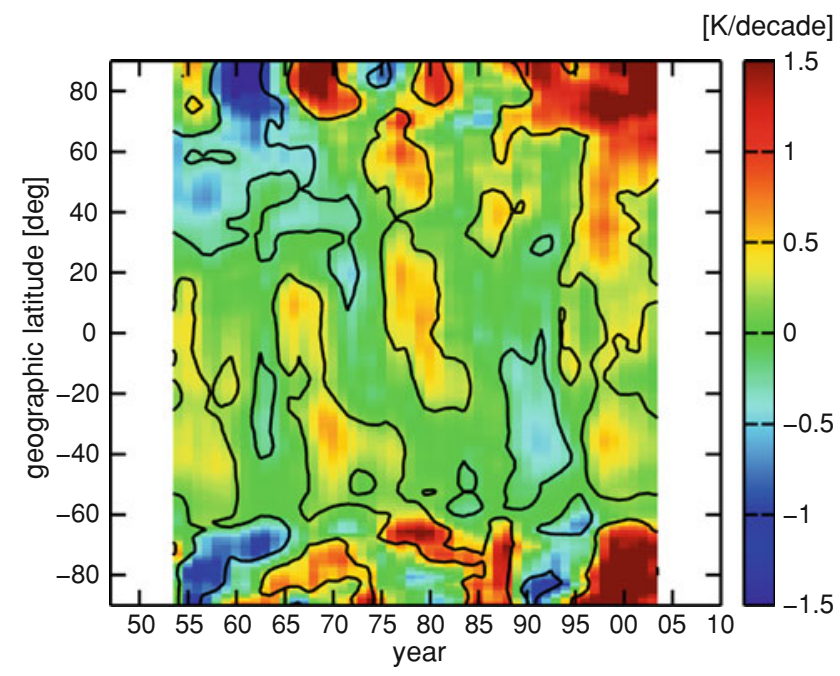

Fig. 4 Linear trend of surface air temperature as function of time and latitude, derived from global NCEP/NCAR reanalysis data by means of a moving 11-year window. The black contour lines mark the areas where the absolute value of the trend exceeds the $90 \%$ significance level (1.6-fold of the standard deviation of the deseasonalized time series) 
1 year-step over the data of Fig. 3. The black contour lines mark the areas where the trend exceed the $90 \%$ significance level (1.6-fold of the standard deviation of the deseasonalized time series). Since the mid 1990s, significant positive trends appear at almost all latitudes. Multidecadal variations and reversals of the trends are present in some regions. Since the anomaly plot (Fig. 3) provides more information on temporal variations than the trend plot (Fig. 4), we only show anomaly plots in the following sections.

\subsection{Sea surface temperature and surface pressure}

The anomaly of sea surface temperature has been derived analogously and is shown in Fig. 5. Additionally, zonalmean surface pressure anomalies (including pressure over continents and sea) are superposed by contour lines (negative values are shown by magenta lines and positive values by black lines with a spacing of $0.4 \mathrm{hPa}$ ). Similar as for the air temperature, a sudden change of surface pressure occurs in the Antarctic around 1980 . From $40^{\circ} \mathrm{S}$ to $60^{\circ} \mathrm{N}$ a slight increase of surface pressure is present (1975-2008: $+0.06 \pm 0.07 \mathrm{hPa} /$ decade), while the Arctic shows a decrease of surface pressure with time $(-0.25 \pm 0.21 \mathrm{hPa} /$ decade) but not as strong as in the Antarctic (1975 to 2008: $-0.37 \pm 0.29 \mathrm{hPa} /$ decade). However, the uncertainties in surface pressure trends are as high as the trends themselves.

It is obvious that many structures of the surface pressure are mirrored in the sea surface temperature and vice versa. The event of ENSO 1997/1998 is manifested by increases of surface pressure and sea surface temperature from low to

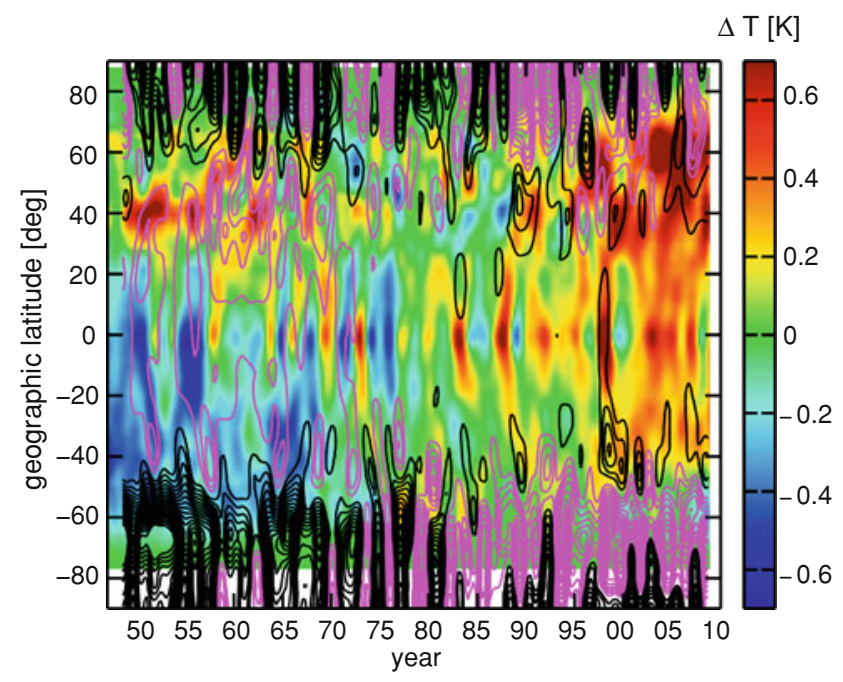

Fig. 5 Anomaly of sea surface temperature (Eq. 1) is shown by the colors while the anomaly of surface pressure is given by the magenta (negative) and black (positive) contour lines with a spacing of $0.4 \mathrm{hPa}$. The pressure increase at $40^{\circ} \mathrm{N}$ around 1990 marks the start of a warm phase of the sea surface at northern mid-latitudes middle latitudes. The sea surface temperature shows interannual oscillations, sometimes symmetrically progressing from low to middle latitudes in both hemispheres. This is most obviously for the equatorial SST increase around 1987 which seems to be connected with SST increases at southern and northern mid-latitudes around 1990. In reality the heat flow propagates on various pathways through gyres and eddies of the ocean surface from low to high latitudes where return flows and overturning circulations happen. Generally, a positive trend of the global mean of sea surface temperature is present (19752008: $+0.12 \pm 0.01 \mathrm{~K} /$ decade) which is a bit smaller than the trend of the global mean surface air temperature (19752008: $+0.18 \pm 0.06 \mathrm{~K} /$ decade). The mean trend of surface air temperature over oceans is $+0.06 \pm 0.01 \mathrm{~K} /$ decade which is just the half of the SST trend. On the other hand, the mean trend over continents is $+0.05 \pm 0.01 \mathrm{~K} /$ decade. It is curious that the global mean trend of surface air temperature is three times larger than the trends over continents or sea, but the land mask removes major parts of the Arctic and the sea mask removes Antarctica which are regions of strong warming in NCEP/NCAR reanalysis. A rough evaluation of Fig. 3.4a of the IPCC Climate Change 2007 report suggests a global trend of $+0.16 \mathrm{~K} /$ decade for SST from 1980 to 2005 (based on HadSST2, HadMAT, TAR SST) (IPCC 2007; Rayner et al. 2006).

At northern midlatitudes the sea surface temperature has a warm phase from 1950 to 1965 , a cold phase from 1965 to 1990 . After a sudden increase of surface pressure around 1990, the sea surface warms up. Historical time series of meteorological stations provide a better overview on interdecadal oscillations and trends in surface pressure and can be utilized in addition to the NCEP/NCAR reanalysis data. An average positive trend of surface pressure of around $0.18 \mathrm{hPa}$ per decade has been observed at Bern $\left(47^{\circ} \mathrm{N}, 7^{\circ} \mathrm{E}\right)$ since 1870 , with phases of accelerated pressure increase around 1940 (1 hPa/decade) and around 1985 ( $2 \mathrm{hPa} /$ decade). A network of Alpine meteorological stations measured a trend of $0.15 \mathrm{hPa}$ per decade (at low elevated stations) during the 20th century (Auer et al. 2007). World maps of linear pressure trends show that a large positive pressure trend occurs at northern midlatitudes over Atlantic and Europe (Gillett et al. 2005). Climate model simulations have attributed the positive pressure trends at low and mid-latitudes to the influence of anthropogenic greenhouse gas emissions (Gillett et al. 2005; Shindell et al. 1999).

\subsection{Intensification of the Southern Polar front jet}

The southern boundary (around $50^{\circ} \mathrm{S}$ ) of the anomaly of the sea surface temperature coincides with the sharp latitudinal gradient of the anomaly of surface pressure in 
Fig. 5. This may result from the coupling between the Southern polar front jet (related to the latitudinal pressure gradient) and the ocean circulation. A modeling study implies that the poleward intensification of the eastward surface wind reduces the stratification of the ocean, allowing the ocean to remove additional heat and anthropogenic carbon dioxide from the atmosphere, but with the penalty of a stronger sea level rise (Russell et al. 2006).

Because of the Earth's topography the eastward wind jet is much stronger in the Southern Hemisphere (annual zonal average is around $8 \mathrm{~m} / \mathrm{s}$ at $1,000 \mathrm{hPa}$ ) than in the Northern Hemisphere (around $2 \mathrm{~m} / \mathrm{s}$ ). An intensification of the anomaly of the Southern polar wind jet (at the surface) is shown by the change from magenta (negative) to black (positive) contour lines in Fig. 6. The eastward wind increases by around $0.5 \mathrm{~m} / \mathrm{s}$ at $60^{\circ} \mathrm{S}$ from 1975 to 2008 corresponding to a linear trend of $+0.16 \pm 0.08 \mathrm{~m} / \mathrm{s}$ per decade (spacing of contour lines is $0.3 \mathrm{~m} / \mathrm{s}$ ). The Southern polar front jet may interact with the ocean circulation, the water vapour loading of the tropical troposphere, and the stratospheric polar vortex. Thus the Southern polar front jet is a key factor for understanding and modeling of the response of the system of ocean, troposphere, and stratosphere to external forcings such as greenhouse warming and ozone depletion (Hartmann et al. 2000).

\subsection{Increase of column-integrated water vapour}

The anomaly of IWV is shown by the colors in Fig. 6 . The strongest positive trends of IWV are in the tropics and in

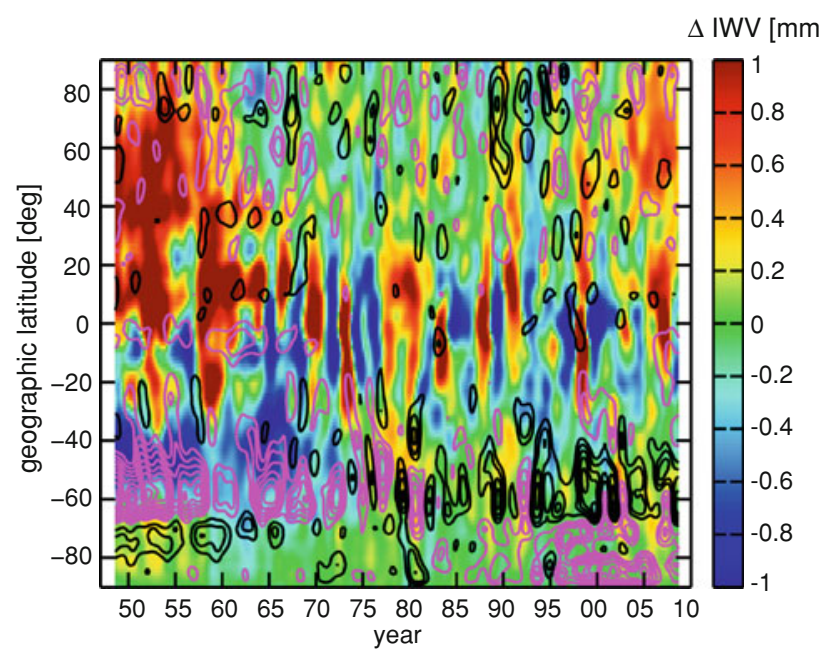

Fig. 6 Anomaly of column-integrated water vapour IWV (equation 1) is shown by the colors while the anomaly of eastward surface wind $(u-\langle u>$ ) is given by the magenta (negative) and black (positive) contour lines with a spacing of $0.3 \mathrm{~m} / \mathrm{s}$. Temporal variations of the Southern polar front jet at $60^{\circ} \mathrm{S}$ seem sometimes related to temporal variation of equatorial IWV. ENSO 1997/1998 is obvious in both, in IWV and the Southern polar front jet the Northern Hemisphere. The interannual oscillations of IWV are partly related to the intensity of the Southern polar front jet. IWV of the Northern Hemisphere increased by about $+0.12 \pm 0.23 \mathrm{~mm} /$ decade in the Northern Hemisphere. Trenberth et al. (2005) derives a larger trend of about $+0.40 \pm 0.09 \mathrm{~mm} /$ decade for the global ocean from 1988 to 2003 using SSM/I satellite data. Contrary the IWV data of Fig. 6 provide a zero trend of $0.00 \pm 0.02 \mathrm{~mm} /$ decade for the global mean series (ocean and land) over the same time interval. IWV over all oceanic areas has a small negative mean trend of $-0.04 \pm 0.09 \mathrm{~mm} /$ decade for NCEP/NCAR reanalysis from January 1988 to January 2003. As already mentioned, IWV of NCEP/NCAR reanalysis is a type $\mathrm{B}$ variable and less reliable. However the estimated trend uncertainty $( \pm 0.09 \mathrm{~mm} / \mathrm{decade})$ is in perfect agreement with Trenberth et al. (2005) indicating a similar strength of IWV fluctuations in both data sets. The uncertainties of the IWV trends of NCEP/NCAR reanalysis are higher than the derived IWV trends of NCEP/NCAR reanalysis. A reliable trend determination of IWV is also handicapped by a strong natural variability of atmospheric water vapour which increases the standard deviation of the trend.

Trenberth et al. (2005) emphasize that reanalysis data of water vapour before 1970 are of relatively poor quality due to a lack of adequate water vapour measurements. This assumption seems to be supported by Fig. 6 which shows extreme deviations of IWV during the time 1948-1965 with respect to the mean values which have been observed with improved measurement systems after 1970. On the other hand, the reliable surface air temperature also indicated a warm phase in the Northern Hemisphere around 1950 .

Bengtsson et al. (2004) determined the trend of IWV from ERA-40 reanalysis data and were skeptical about its reliability since the trend was twice as high as the trend determined from the Clausius-Clapeyron relation assuming conservation of relative humidity. Contrary, the problem of the IWV data of NCEP/NCAR seems to be an underestimation of the IWV trend if the SSM/I satellite data are correct. The anomaly pattern of IWV in Fig. 6 looks quite similar as those of sea surface temperature and air temperature. However the warm phase of sea surface temperature in the Northern Hemisphere around 1950 is probably too small to account for the coincident high IWV values in Fig. 6. The increase of IWV at $40^{\circ}$ to $60^{\circ} \mathrm{N}$ since 2003 is not so strong as the increase of saturation water vapour pressure (depending on the air temperature) would suggest according to the Clausius-Clapeyron relation. Thus a negative anomaly of surface relative humidity occurs in spite of the increase of IWV in the Northern Hemisphere (Fig. 7). 


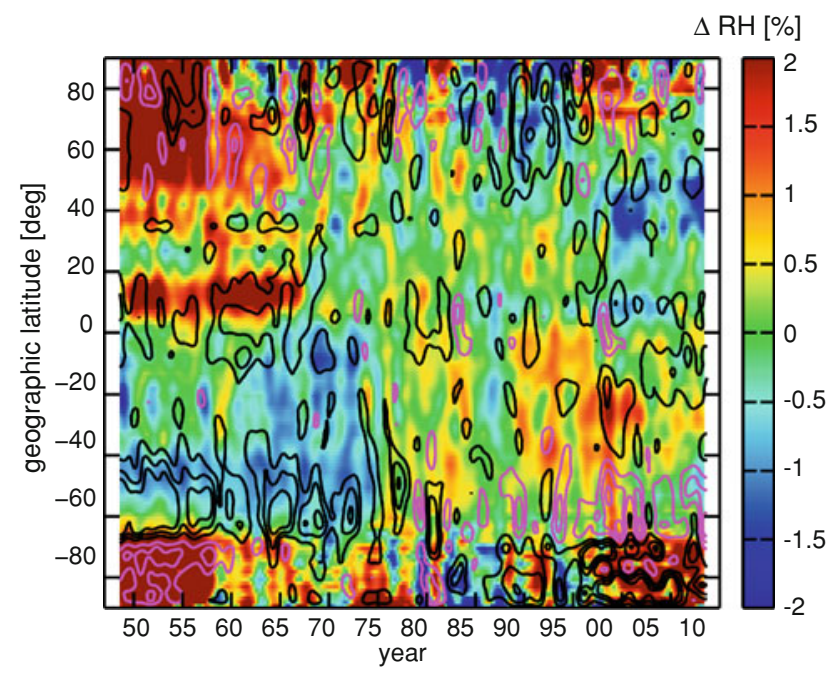

Fig. 7 Anomaly of surface relative humidity RH (Eq. 1) is shown by the colors while the anomaly of northward surface wind $(v-<v>$ ) is given by the magenta (negative) and black (positive) contour lines with a spacing of $0.2 \mathrm{~m} / \mathrm{s}$. The ENSO 1997/1998 increased the surface relative humidity of the Southern Hemisphere and caused a strong acceleration of the Southern Ferrel and polar cells (position of cells and signs of $\langle v\rangle$ are in Fig. 1

\subsection{Surface relative humidity and meridional surface wind}

Climate modelers often emphasize that relative humidity is a climate parameter which tends to be conserved during the global warming process (Held and Soden 2006; Trenberth et al. 2005). Since a trend study of a constant parameter is boring, there are only few trend studies on time series of locally observed surface relative humidity in the literature (Gaffen and Ross 1999). The Hovmöller diagram of the anomaly of surface relative humidity of NCEP/NCAR reanalysis is depicted in Fig. 7 and contains variations up to $1-2 \%$ per decade.

The global mean trend of surface relative humidity from 1975 to 2008 is $-0.01 \pm 0.04 \%$ per decade (Fig. 7). However the zero trend of the global mean is due to the superposition of a negative trend in the Northern Hemisphere and a positive trend in the Southern Hemisphere, and this is certainly of interest for an assessment of the consequences of global warming to the hydrological cycle. The trend of the Northern Hemisphere is $-0.13 \pm 0.04 \%$ per decade, and the trend of the Southern Hemisphere is $+0.11 \pm 0.10 \%$ per decade (trends are expressed in the unit of relative humidity which is [\%]).

Thus the increase of water vapour pressure in the Northern Hemisphere did not completely follow the rapid warming (increase of saturation vapour pressure) of the Northern Hemisphere so that the relative humidity slightly decreased in the last decades. This trend result is uncertain since relative humidity is a less reliable type $\mathrm{B}$ variable of
NCEP/NCAR reanalysis. On the other hand the assumption of a conserved relative humidity during the global warming process seems to be too simple and might be only fulfilled over oceans while the Northern Hemisphere has a considerable fraction of land areas.

The anomaly of northward surface wind $(v-<v>)$ is given by the magenta (negative) and black (positive) contour lines with a spacing of $0.2 \mathrm{~m} / \mathrm{s}$ in Fig. 7. It is obvious that the ENSO 1997/1998 accelerated the Southern Ferrel and polar cells. The position of the meridional circulation cells and the signs of $\langle v\rangle$ are shown in Fig. 1. The southward winds of the Southern Ferrel cell and the northward winds of the Southern polar cells are intensified during ENSO 1997/1998. The higher surface winds are closely related with an increase of surface relative humidity in Fig. 7. Snow accumulation records derived from Antarctic ice cores contain a strong ENSO signal but the oceanic and atmospheric paths on which the ENSO signal arrives at Antarctica are not well understood (Turner 2004). The Hovmöller diagram of NCEP/NCAR reanalysis in Fig. 7 indicates that acceleration of the meridional tropospheric circulation cells leads to a teleconnection of ENSO in the tropics and extratropics of the Southern Hemisphere. The ENSO signal seems to appear coincidently in the anomalies of meridional wind and surface humidity at low, middle, and high latitudes (Fig. 7).

One reviewer pointed out that the strong increase of surface relative humidity and surface air temperature in Antarctica after 1997 is not consistent with the ClausiusClapeyron relation since IWV is almost constant over Antarctica after 1997. We would interprete the strange behaviour of surface relative humidity and IWV by a vertical redistribution of humid air from upper to lower altitudes and dry air from the surface to upper altitudes which might be a consequence of the acceleration of the polar cells. However the Hovmöller diagrams show zonal means of climate anomalies, and misinterpretations of 3-D transport processes by 2-D Hovmöller diagrams cannot be excluded.

\section{Conclusions}

The simultaneous discussion of the trends and variability of the global fields of seven climate parameters is an unusual broad approach and is complementary to specified climate trend studies which concentrate on one parameter and/or on a special region. A broad approach may give a more complete picture of the climate system. Reanalysis data can inspire and validate climate modeling. The dynamic visualization of oceanic and atmospheric anomalies of the reanalysis data gives insight into the ocean-atmosphere system. 
Hovmöller diagrams of climate anomalies show interdependencies of all selected parameters from sea surface temperature to column-integrated water vapour. The diagrams consistently reveal teleconnections between equatorial and polar regions. The ENSO 1997/1998 event seems to accelerate the Southern circulation cells and is accompanied by enhanced surface air pressure at mid-latitudes (Figs. 5, 6, 7). The Southern polar front jet shows an increase of eastward surface wind during the past 60 years (Fig. 6). Stratospheric ozone depletion, greenhouse warming, or other external forcings possibly induce interactions between the Southern polar front jet and the polar stratospheric vortex which could result in rapid climate changes (Hartmann et al. 2000). Positive anomalies of surface relative humidity and northward surface wind occur over Antarctica since 1997 (Fig. 7) and may indicate such a rapid climate change. The series of meridional surface wind of NCEP/NCAR also suggest the existence of timedependent, double polar cells. Sudden changes in climate parameters are often related to circulation changes and might be used as precursors of warm or cold phases (e.g., surface pressure change around 1990 at northern mid-latitudes). These initial results show that Hovmöller diagrams of climate anomalies are efficient for climate diagnostics and climate change research.

Additionally, Hovmöller diagrams can be utilized for intercomparisons of models, reanalyses, and observational data sets. While climate anomalies should occur at the same time in all data sets, time-dependent systematic errors of models, reanalyses, and observing systems often differ in the time of appearance. Hovmöller diagrams may pinpoint the occurrence of time-dependent systematic errors. Such errors are most critical for reliable trend analyses. We plan intercomparisons of various data sets in order to explore the potential of Hovmöller diagrams for data harmonization and quality control.

Acknowledgments We are grateful to the Swiss Global Atmosphere Watch program (GAW-CH) for support of the study within the project SHOMING. Motivation and advices came from working groups of GEOMON (European Union), COST WaVaCS (European Cooperation in Science and Technology), and International Space Science Institute (Bern, $\mathrm{CH}$ ). We owe thanks to the Climate Diagnostics Center of NOAA's Earth System Research Laboratory, the NCEP/NCAR Reanalysis 1 project, and the ICOADS project (data were provided by NOAA/OAR/ESRL PSD, Boulder, Colorado, USA). Finally we thank the three reviewers for their constructive comments and many improvements.

\section{References}

Auer I et al (2007) HISTALP-historical instrumental climatological surface time series of the Greater Alpine Region. Int J Climatol $27: 17-46$
Bengtsson L, Hagemann S, Hodges KI (2004) Can climate trends be calculated from reanalysis data? J Geophys Res 109: D11111. doi: 10.1029/2004JD004536

Chen J, Bosilovich MG (2007) Hydrological variability and trends in global reanalyses. 19th Conference on climate variability and change, San Antonio, TX, USA

Comiso JC (2003) Warming trends in the Arctic from clear sky satellite observations. J Clim 16:3498-3510

Dall'Amico M, Stott PA, Scaife AA, Gray LJ, Rosenlof KH, Karpechko AY (2009) Impact of stratospheric variability on tropospheric climate change. Clim Dyn. doi:10.1007/s00382009-0580-1

Gaffen DJ, Ross RJ (1999) Climatology and trends of US surface humidity and temperature. J Clim 12:811-828

Gillett NP, Allan RJ, Ansell TJ (2005) Detection of external influence on sea level pressure with a multi-model ensemble. Geophys Res Lett 32:19714 doi:10.1029/2005GL023640

Hansen J et al (2007) Climate simulations for 1880-2003 with GISS modelE. Clim Dyn 29:661-696. doi:10.1007/s00382-007-0255-8

Hartmann DL, Wallace JM, Limpasuvan V, Thompson DWJ, Holton JR (2000) Can ozone depletion and global warming interact to produce rapid climate change? In: Proceedings of the National Academy of Science (PNAS), vol 97, pp 1412-1417

Held I, Soden BJ (2006) Robust response of the hydrological cycle to global warming. J Clim 19:5686-5699

Hovmöller E (1949) The trough and ridge diagram. Tellus 1:62-66

IPCC (2007) Climate change 2007: the physical science basis, report of the intergovernmental panel on climate change. In: Solomon et al S (ed), Cambridge University Press, p 996

Kalnay E et al (1996) The NCEP/NCAR reanalysis project. Bull Am Meteorol Soc 77:437-471

Kistler R et al (2001) The NCEP-NCAR 50-year reanalysis: monthly means CD-ROM and documentation. Bull Am Meteorol Soc $82: 247-267$

Martius O, Schwierz C, Davies HC (2006) A refined Hovmöller diagram. Tellus 58A:221-226

Maunder EW (1904) Note on the distribution of sun-spots in heliographic latitude, 1874-1902. Mon Not R Astron Soc 64:747-761

Max N, Crawfits R, Williams D (1993) Visualization for climate modeling. IEEE Comput Graph Appl 13(4):34-40

Peterson TC, Baringer MO (2009) State of the climate in 2008. Bull Am Meteorol Soc 90:1-196. doi:10.1175/BAMS-908-StateoftheClimate

Raschke E, Bakan S, Kinne S (2006) An assessment of radiation budget data provided by the ISCCP and GEWEX-SRB. Geophys Res Lett 33:L07812. doi:10.1029/2005GL025503

Rayner NA, Brohan P, Parker DE, Folland CK, Kennedy JJ, Vanicek M, Ansell TJ, Tett SFB (2006) Improved analyses of changes and uncertainties in sea surface temperature measured in situ since the mid-nineteenth century: The HadSST2 dataset. J Clim 19:446-469

Russell JE, Dixon KW, Gnanadesikan A, Stouffer RJ, Toggweiler JR (2006) The Southern Hemisphere westerlies in a warming world: propping open the door to the deep ocean. J Clim 19:6382-6390

Shenoi BA (2006) Introduction to digital signal processing and filter design. Wiley, NJ, USA

Shindell DT, Miller RL, Schmidt GA, Pandolfo L (1999) Simulations of recent northern winter climate trends by greenhouse-gas forcing. Nature 399:452-455

Simmons AJ, Jones PD, da Costa Bechtold V, Beljaars ACM, Kallberg PW, Saarinen S, Uppala SM, Viterbo P, Wedi N (2004) Comparison of trends and low-frequency variability in CRU, ERA-40, and NCEP/NCAR analyses of surface air temperature. J Geophys Res 109:D24115. doi:10.1029/2004JD005306 
Steig EJ, Schneider DP, Rutherford SD, Mann ME, Comiso JC, Shindell DT (2009) Warming of the Antarctic ice-sheet surface since the 1957 International Geophysical Year. Nature 457:459-463

Trenberth KE, Fasullo J, Smith L (2005) Trends and variability in column-integrated atmospheric water vapor. Clim Dyn 24:741-758

Tung KK, Camp CD (2008) Solar cycle warming at the Earths surface in NCEP and ERA-40 data: a linear discriminant analysis. J Geophys Res 113:D05114. doi:10.1029/2007JD009164
Turner J (2004) The El Nino-Southern Oscillation and Antarctica (Review). Int J Climatol 24:1-31

Willett KM, Gillett NP, Jones PD, Thorne PW (2007) Attribution of observed surface humidity changes to human influences. Nature 449:710-712 